\title{
Accounting for External Turbulence of Logistics Organizations via Performance Measurement Systems
}

Bühler, Andreas; Wallenburg, Carl Marcus; Wieland, Andreas

\author{
Document Version \\ Accepted author manuscript \\ Published in: \\ Supply Chain Management: An International Journal
}

DOI:

10.1108/SCM-02-2016-0040

Publication date:

2016

License

Unspecified

Citation for published version (APA):

Bühler, A., Wallenburg, C. M., \& Wieland, A. (2016). Accounting for External Turbulence of Logistics Organizations via Performance Measurement Systems. Supply Chain Management: An International Journal, 21(6), 694-708. https://doi.org/10.1108/SCM-02-2016-0040

Link to publication in CBS Research Portal

\section{General rights}

Copyright and moral rights for the publications made accessible in the public portal are retained by the authors and/or other copyright owners and it is a condition of accessing publications that users recognise and abide by the legal requirements associated with these rights.

\section{Take down policy}

If you believe that this document breaches copyright please contact us (research.lib@cbs.dk) providing details, and we will remove access to the work immediately and investigate your claim. 


\title{
Accounting for External Turbulence of Logistics Organizations via Performance Measurement Systems
} Andreas Bühler, Carl Marcus Wallenburg, and Andreas Wieland

\author{
Journal article (Post print version)
}

CITE: Accounting for External Turbulence of Logistics Organizations via Performance Measurement Systems. / Bühler, Andreas; Wallenburg, Carl Marcus; Wieland, Andreas. In: Supply Chain Management, Vol. 21, No. 6, 2016.

DOI: 10.1108/SCM-02-2016-0040

Uploaded to Research@CBS: November २०16 


\title{
Accounting for external turbulence of logistics organizations via performance measurement systems
}

Andreas Bühler, Carl Marcus Wallenburg, Andreas Wieland

\begin{abstract}
Purpose - To investigate the role of upper management in designing performance measurement systems (PMS) that account for external turbulence of the organization, and to show how this PMS design for turbulence impacts organizational resilience and distribution service performance.
\end{abstract}

Design/methodology/approach - Hypotheses are developed by integrating management accounting and strategic management perspectives into SCM and subsequently tested based on data from 431 logistics organizations (i.e., both logistics companies and internal logistics departments of manufacturing and retailing companies).

Findings - An attention focusing usage type of the PMS by the upper management fosters incorporating the element of risk into the PMS of the company. Further, PMS design for turbulence enhances organizational resilience and, indirectly, this also leads to improved distribution service performance.

Originality/value - This article is the first to introduce the concept of PMS design for turbulence to the literature and to show that it is relevant for supply chain risk management by fostering the capabilities and the performance of logistics organizations. Further, it is shown that a seemingly detached issue like the general PMS use focus of the upper management impacts supply chain risk management.

Keywords: Organizational Resilience, Performance Measurement System, Supply Chain Risk Management, Logistics Service Providers 


\section{Introduction}

During recent years, an increasing level of turbulence has fundamentally challenged the assumption of stability in traditional supply chain management (SCM) practice (Christopher and Holweg, 2011; Malik et al., 2011; Abrahamsson et al., 2015), and demand and supply market turbulence has increasingly been accepted to be a major source of supply chain risk (Braunscheidel and Suresh, 2009; Blome and Schoenherr, 2011). Indeed, in seeking new approaches to cope with turbulence caused by suppliers and customers as well as with disruptions of material flow, supply chain risk management (SCRM) has become a major area of SCM research (Christopher et al., 2011; Sodhi et al., 2012; Wieland et al., 2016). SCRM can be viewed as "the implementation of strategies to manage both everyday and exceptional risks along the supply chain based on continuous risk assessment with the objective of reducing vulnerability and ensuring continuity” (Wieland and Wallenburg, 2012, p. 890 f).

Consistent with this view, many authors have focused on risk identification, on risk assessment, and especially on mitigation and contingency strategies to control risk (e.g., Ponomarov and Holcomb, 2009; Sodhi et al., 2012; Scholten et al., 2014). In contrast, constant monitoring of risk as a further element of a comprehensive SCRM process has, so far, been much neglected in the literature. Such risk monitoring aims at sensing new important factors and updating initial risk assessments (Hallikas et al., 2004) and involves "the imperative to devise and develop appropriate performance measures and metrics to evaluate, educate and direct the operational and strategic decisions” (Ritchie and Brindley, 2007, p. 304).

To make the monitoring of external turbulence an integral part of existing management control processes, it is of pivotal importance to account for corresponding metrics in designing 
an organization's performance measurement system (Kennerley and Neely, 2003; Neely et al., 2005; Ritchie and Brindley, 2007; Björklund et al., 2012; Rasid et al., 2012). Correspondingly, Christopher and Holweg (2011) have proposed that higher levels of turbulence "will require revisiting the management accounting procedures that are used to evaluate different supply chain decisions” (p. 64).

As highlighted by Henri (2008), a performance measurement system (PMS) typically plays three roles: (1) It is an outcomes surveillance mechanism, (2) it is a management support tool, and (3) it institutionalizes organizational processes. Hence, a PMS not only serves to measure performance outcomes (cf., van Hoek, 2000), but also to provide insights regarding factors that influence performance (i.e., performance drivers), including relevant aspects from the external context of the company. Yet, anecdotal evidence shows that far from all logistics organizations (both logistics companies and departments of manufacturing and retailing companies) actually have incorporated metrics that reflect external turbulence when designing their PMS.

Against this background, this article integrates management accounting and strategic management theory into SCM to address its two research objectives: The first objective focuses on the outcome of PMS design for turbulence. We argue that accounting for external turbulence via metrics in PMS design is beneficial for logistics organizations and show to what extent it increases organizational resilience and the distribution service performance of the companies.

The second objective of this research focuses on the antecedents of PMS design for turbulence. Building on Henri’s (2006) concept of upper management control and PMS design, we demonstrate that the approach which the upper management of an organization has towards how 
to use the PMS in general will strongly impact the extent to which an organization incorporates risk metrics into its PMS. ${ }^{1}$

This article is organized as follows. First, we present the concepts covered in our study. After outlining the theoretical framework of the research model and deriving the hypotheses, we show the results of our analysis that was based on empirical data collected from 431 logistics organizations (180 logistics companies and 251 logistics departments of manufacturing and retailing companies). Finally, theoretical and managerial implications of the findings are discussed and avenues of future research are proposed.

\section{Conceptual framework and hypotheses}

\section{Dependent Variables}

Before outlining our conceptual model and its hypotheses, we will give a brief overview of the primary constructs of this study, which will be used in the hypotheses development afterwards. We will start with the dependent variables of the conceptual model.

PMS design for turbulence (while this concept refers to external turbulence, it is called PMS design for turbulence for reasons of brevity) is the central element in the conceptual model. It is a concept that has not yet been discussed in the literature. We define it as the degree to which the design of an organization’s PMS encompasses risk metrics to account for external turbulence and to monitor the potential impacts of this turbulence. Such metrics, in seeking to reveal the increasing risks in the supply chain context and the need for new responses to manage these risks, will help front-line managers to make decisions with the right information at the right time (Gunasekaran and Kobu, 2007). In this context, it should be noted that a PMS refers to any structured

\footnotetext{
${ }^{1}$ It should be noted already at this point that the observed effects in the empirical model do not differ between standalone logistics companies and internal logistics departments of manufacturing and retailing companies as described in the results section.
} 
set of performance measures used to quantify the efficiency and effectiveness of operations in the respondents' respective logistics organization (we refer to Ridgway, 1956 and Kilfoyle et al., 2013 for theorizations of such systems). Consistent with the general understanding on PMS, this does not need to be a technologically sophisticated management information system, but can also be simpler applications like visual KPI scoreboards or spreadsheets.

Organizational resilience as a first outcome of PMS design for turbulence is the ability of an organization to cope with turbulence and has been described as being "at the heart of current supply chain management thinking” (Melnyk et al., 2014). Following Ponomarov and Holcomb (2009), it can also be described as "the capacity to adjust and maintain desirable functions under challenging or straining conditions” (p. 128). While recent research has mainly focused on the concept of supply chain resilience from an inter-organizational perspective (e.g., Christopher and Holweg, 2011; Ambulkar et al., 2015), this research focuses on the resilience of individual logistics organizations, i.e., both internal logistics departments of manufacturing and retailing companies as well as logistics companies.

Distribution service performance refers to the overall fulfillment of customer expectations in logistics operations (Ellinger et al., 2000; Springinklee and Wallenburg, 2012). Within the costservice tradeoff of SCM, it focuses on the quality of service that is key to creating customer satisfaction (Rhea and Shrock, 1987; Mentzer et al., 2012). This research looks at distribution service performance as the key outcome of a logistics organization that affects the performance of other supply chain members, and ultimately overall supply chain performance (Cooper et al., 1997). 


\section{Independent Variables}

Before introducing the independent variables, different PMS usage types discussed in the accounting and management control literature should briefly be described for readers not familiar with this literature: In his seminal work, Henri (2006) outlined that the way in which the upper managers of a company (i.e., top executives, not the mid-level operational managers; Carpenter et al., 2004) use the PMS is a relevant contingent factor for the design of this PMS as well as for the selection of performance metrics. In this domain, the accounting-related literature has provided various classifications of managerial PMS use. This includes differentiations between score carding, problem solving, and attention directing (Simon et al., 1954), between an instrumental, conceptual, and symbolic use (Menon and Varadarajan, 1992) as well as a diagnostic and interactive use (Simons, 1990). Vandenbosch (1999), in extending Simon et al.'s (1954) framework, differentiated between a score keeping, problem solving, attention focusing, and legitimizing use of PMS.

Building on these different classifications from an SCRM perspective, the two most contrary types of PMS use are an (interactive) attention focusing use, which aims at empowering an organization, and a (diagnostic) score keeping use, which aims at controlling an organization (Vandenbosch, 1999; Henri, 2006). These two types of PMS reflect very different managerial mindsets regarding the role PMS has in managing the organization (Simon et al., 1954; Vanden-

bosch, 1999; Koufteros et al., 2014). In that sense, these two types of PMS use constitute-as we will express in the hypotheses of our conceptual model—contingent factors that influence the use of supply chain risk metrics in an organization. The two use types are reflected via the two independent variables of the conceptual model: 
Attention focusing refers to an interactive PMS use that fosters organizational dialogue (Simons, 1990), where the guiding question is: "What problems should we look into?” (Simon et al., 1954; Henri, 2006). For upper managers pursuing an attention focusing use of performance metrics, PMS will serve as an "ammunition machine” (Burchell et al., 1980, p. 15) to proactively direct employees' attention towards critical success factors and uncertainties (Henri, 2006). Within the PMS use classification by Menon and Varadarajan (1992), attention focusing represents a conceptual use that fosters the awareness and understanding of specific situations (Schaeffer and Steiners, 2003), e.g. critical success factors and uncertainties (Henri, 2006). Organizations where the upper management emphasizes the use of PMS for attention focusing will try to design their PMS in a way that allows identifying new risk developments such as the monitoring of external turbulence.

Score keeping represents a diagnostic PMS use (Simons, 1990) for reporting and surveillance (Feldman and March, 1981), where the guiding question is: "How am I doing?" (Simon et al., 1954). It focuses on a reactive cybernetic logic that compares operating results to prior expectations and provides feedback for potential future corrections (Hofstede, 1978). In other words, a score keeping PMS use focuses on comparing outcomes to expectations (Vandenbosch, 1999). Hence, for upper managers pursuing a score keeping use of PMS, performance metrics will serve as a routine control measure to follow-up with predefined goals (Vandenbosch, 1999; Henri, 2006). Organizations where the upper management emphasizes a score keeping use of PMS will tend to discourage forward looking activities like the monitoring of external turbulence.

Although managers often focus primarily on one or the other usage, attention focusing and score keeping are not mutually exclusive. This observation is in line with the current trend in 
PMS research not to see each way to measure performance separately, but rather as part of a “package” (Malmi and Brown, 2008). Indeed, in spite of their different focuses, managers will often use PMS in multiple ways.

\section{Development of Hypotheses}

The conceptual model developed by this research is displayed in Figure 1. It builds on two theoretical domains.

The outcome part of the model (i.e., hypotheses 1, 2 and 3) refers to the first objective of this research and incorporates the resource-based view (Barney, 1991) to argue the causal relationships between PMS design for turbulence, organizational resilience, and distribution service performance as a resource-capability-performance link (Springinklee and Wallenburg, 2012). This link was already incorporated by Amit and Schoemaker (1993) and Grant (1991), who stated that “while resources are the source of an organization's capabilities, capabilities are the main source of its competitive advantage” (p. 119). Based on this argumentation, PMS design for turbulence as a resource will foster organizational resilience as a capability, which, in turn, enhances the distribution service performance.

The antecedent part of the model (i.e., hypotheses 4 and 5), which will be addressed after the outcome part of the model, refers to the second objective of the paper. It builds on Henri's (2006) concept of upper management control impact on PMS design and investigates how the focus of upper management's PMS use either acts as a driver of or as an impediment to PMS design for turbulence. Here, we argue that an upper management that uses a PMS to focus the attention of the organization will foster the inclusion of supply chain risk metrics into the PMS, while a focus on score keeping will hamper its inclusion. 
Regarding the outcomes, the connection between PMS design for turbulence and organizational resilience reflects a resource-capability link. According to the resource-based view, resources are defined as factors controlled by the firm that enable enhanced efficiency and effectiveness (Tomer, 1987; Barney, 1991). From this perspective, PMS design for turbulence constitutes an organizational capital resource (Tomer, 1987) that enables an organization to better sense changes in its environment. Capabilities reflect the ability of an organization to assemble and deploy resources to create competitive advantage (Amit and Schoemaker, 1993). As Daugherty et al. (2009) stated, "capabilities are what firms do with assets” (p. 2); indeed, they can be considered "intermediate goods" (Amit and Schoemaker, 1993).

In seeking ways to manage higher levels of external turbulence, logistics organizations need to monitor supply chain risks through appropriate performance metrics (Rasid et al., 2012). A PMS that integrates such forward-looking risk metrics is an intangible resource that provides an organization with early warning signals. In order to manage daily operations, front-line logistics managers-in following up with the initial identification and assessment of risk sources—need to constantly keep track of potentially negative operational impact. Though it remains a challenge to assess the probability of supply chain risks and their impact (Wagner and Bode, 2008), PMS design for turbulence will be an important foundation for such a constant monitoring of risk. Risk metrics will inform operational decision-makers as well as workers about the current state of identified risk sources and thus sharpen organizational awareness. Regarding the coordination of SCRM across departments, front-line managers from different departments will better 
collaborate when sharing the same view on turbulence and one overall risk monitoring process, similarly to other processes of internal relational behavior (Wong et al., 2012).

This way, PMS design for turbulence is valuable as it allows an organization to either anticipate and prevent the occurrence of future change (proactive lever) or to make current change visible and enable fast reactions (reactive lever). These two levers are the components of resilience (Wieland and Wallenburg, 2013; Durach et al., 2015). Looking at the proactive lever, the monitoring of risk will increase organizational resilience by helping an organization to prepare for an external risk, to assess its impact and probability, and to take timely precautions without increasing the level of control perceived among employees that might decrease organizational flexibility (Ignatiadis and Nandhakumar, 2006). In case of an unexpected supply chain event, the reactive risk monitoring lever facilitates quick detection that allows for speedy corrective actions to recover and stabilize operations (Sheffi and Rice, 2005; Wieland and Wallenburg, 2012) and, in that way, increases resilience. It should be noted here that managers who rely too much on their PMS could become negligent, which might create a false sense of security. Overall, however, incorporating supply chain risk metrics in the overall PMS will put a logistics organization in a position to cope with external turbulence and thus minimize their vulnerability.

To sum up and referring to the four attributes that, according to the RBV (Barney, 1991, 2012), are needed for a resource to hold the potential of sustained competitive advantage, PMS design for turbulence is (1) valuable, as it enables counteracting turbulence in an organization's environment, (2) rare, as so far only few organizations have incorporated this feature in their PMS, (3) imperfectly imitable, as there is causal ambiguity for the resource-capability link that is difficult to analyze for competitors, and finally (4) non-substitutable, as there are typically no other valuable resources that provide the same sensing and reaction possibilities effect as PMS 
design for turbulence. We therefore argue that PMS design for turbulence, by providing a constant monitoring of external risk and facilitating SCRM coordination across departments enhances an organization's resilience in coping with external turbulence. Based on this reasoning, we hypothesize:

H1: PMS design for turbulence has a positive impact on organizational resilience.

The relationship between organizational resilience and distribution service performance constitutes the second part of the resource-capability-performance link, where capabilities are the source of competitive advantage and, with that, of performance. Organizational resilience- the capacity to adjust and maintain functionality under challenging conditions (Ponomarov and Holcomb, 2009)—represents such a capability and provides companies with sustainable competitive advantage (Calantone et al., 2003; Trkman and McCormack, 2009). This applies not only in general, but also specifically for logistics organizations.

Previous research has shown that supply chain glitches can have a very negative influence on shareholder value (Hendricks and Singhal, 2003; Johnson et al., 2013) and a number of conceptual contributions have highlighted the importance of organizational resilience as a distinct source of competitive advantage (Coutu, 2002; Hamel and Välikangas, 2003; Sheffi and Rice, 2005). McCann et al. (2009) provided first empirical insights into the importance of resilience for competitiveness and profitability in turbulent environments, albeit not focusing on the supply chain context. In line with Weick et al.'s (1999) statement that "resilience is not only about bouncing back from errors, it is also about coping with surprises in the moment” (p. 46), Wieland and Wallenburg (2012) have empirically confirmed the importance of both the proactive and reactive dimensions of resilience from an overall supply chain perspective. 
Given these findings, we argue that resilient organizations, which are prepared to cope with external turbulence, will be in a better position to fulfill customer expectations regarding consistently high levels of distribution service performance by mitigating potential negative consequences of turbulence, which have been outlined in prior SCRM research (e.g., Wagner and Bode, 2008). First and foremost, keeping processes stable or recovering quickly, while adapting processes to changed circumstances, will be a critical factor for delivery reliability (Chan et al., 2009). Moreover, in an unstable environment, a resilient organization will better perform in responding to short-term customer requests. For example, it will be prepared to adapt its own delivery quantities to shortages caused by the bullwhip effect or upstream capacity constraints (Sheffi and Rice, 2005) while taking quick action to resolve these shortages. In summary, we propose:

H2: Organizational resilience has a positive impact on distribution service performance.

SCRM has gained significant levels of attention in managerial practice (Sodhi et al., 2012; Simchi-Levi et al., 2014). Already more than ten years ago, many logistics organizations "use[d] formal processes to gather risk metrics for presentations to their boards of directors" (Sheffi and Rice, 2005, p. 48). During recent years, an increasing level of turbulence has fundamentally challenged the assumption of stability in traditional SCM practice (Christopher and Holweg, 2011; Malik et al., 2011) and, in the aftermath of the economic and financial crisis in 2008 and 2009, demand and supply market turbulence has increasingly been accepted to be a major source of supply chain risk (Braunscheidel and Suresh, 2009; Blome and Schoenherr, 2011).

Yet, the use of "formal processes to gather risk metrics for presentations to their boards of directors [...] can go only a limited way toward reducing vulnerability” (Sheffi and Rice, 2005, 
p. 48), as PMS design for turbulence only is a facilitator: Incorporating risk metrics to monitor external turbulence does not deliver performance improvements by itself. As previously outlined, PMS design for turbulence will help an organization to follow up with the initial identification and assessment of risk sources and to keep track of potential effects ahead of their occurrence. However, leveraging risk monitoring information for increased levels of distribution service performance forms part of an organizational learning process. Manuj and Mentzer (2008) emphasize the role of organizational learning in SCRM in "promoting an ongoing stream of dialogue and inquiry, analyzing mistakes, seeking feedback, communicating, and questioning” (p. 148). Thus, with a learning orientation, making use of supply chain risk metrics for superior performance comes only if a company turns such PMS design into an increasing ability to cope with turbulence (i.e., organizational resilience). Therefore, we conclude:

\section{H3: PMS design for turbulence has no direct impact on distribution service performance.}

Henri (2006), in conceptualizing the impact of upper management's control focus on PMS design and the diversity of performance metrics, argued that upper managers, depending on their primary type of PMS use, will not need the same variety of financial and non-financial measures to support their objectives. In using PMS for attention focusing, upper managers seek to foster organizational dialogue and the awareness of critical issues. Hence, the mindset of upper-level managers who prefer an attention focusing use is targeted towards empowering rather than controlling their organization (Vandenbosch, 1999). By selecting performance measures thatbesides tracking progress towards predefined goals—can send signals throughout the organization, they will generally give an important role to non-financial measures that are more actionable than financial measures (Ittner and Larcker, 1998). This includes leading measures that aim at predicting what will happen (Evans, 2004). Henri (2006) found that a key objective of an at- 
tention focusing PMS use is to direct employees' attention on critical uncertainties and that it strongly supports the use of such non-financial measures. Vandenbosch's (1999) results underline upper-level managers' awareness that PMS information can affect what their organization focuses on. In the context of higher levels of external turbulence, upper-level managers with an attention focusing mindset will take a broad view and will be inclined to recognize the role of supply chain risks and the importance of risk metrics as part of a comprehensive SCRM process. Besides fostering the initial identification and assessment of supply chain risk, they will seek to ensure a constant risk monitoring process. Thus, in designing the PMS of their organization, they will proactively foster the integration of supply chain risk metrics. Therefore, we propose:

H4: The degree to which upper management uses PMS for attention focusing has a positive impact on PMS design for turbulence.

A score keeping use of PMS focuses on comparing results with predefined expectations in order to fulfill managers' and stakeholders’ information requirements (Atkinson et al., 1997). In evaluating different types of PMS use, Vandenbosch (1999) found a score keeping use to be negatively related to organizational competitiveness. However, he recognized its raison d'être in the simplicity of being "one of the easiest management information and control systems to develop" (p. 88). Hofstede (1978) states that "standards are often set by higher line management, intervening is the task of lower line management, while the actual process to be controlled is carried out by operating personnel” (p. 452). Hence, the mindset of upper-level managers who prefer a score keeping use is targeted towards controlling rather than empowering their organization. In seeking to establish a standardized reporting routine with a cybernetic control of results, their PMS will include lagging (outcome) measures at the expense of leading (predictive) measures (Evans, 2004). Moreover, given upper-level managers' preference for performance measures that are 
simple and easy to use (Gunasekaran and Kobu, 2007), such a focus on outcomes usually results in a clear dominance of financial measures and a negligence of non-financial measures (Henri, 2006). Consequently, it can be assumed that upper-level managers with a primarily score keeping mindset — even when made aware of the importance of SCRM in a supply chain context with increasing levels of external turbulence-will not be inclined to foster PMS design for turbulence. As part of their reporting to stakeholders, they may provide an initial identification and assessment of supply chain risk, or even define risk mitigation and contingency strategies upfront to control risk. They will, however, be less inclined to recognize front-line managers' need for a constant proactive monitoring of risk through the integration of supply chain risk measures in their organization's PMS. Thus, even in a supply chain context that is characterized by an increasing level of external turbulence, a score keeping PMS use will be an impediment to the design of PMS for supply chain risk. If used at all, risk metrics will play a subordinate role. Therefore, we propose:

H5: The degree to which upper management uses PMS for score keeping has a negative impact on PMS design for turbulence.

\section{Research method}

\section{Sample Design and Characteristics}

As a basis for hypotheses testing, an online survey was conducted to collect primary data from logistics organizations of shippers (manufacturing and retailing companies) as well as logistics service providers in Germany. Following Phillips (1981) in that informants are most reliable when they participate in relevant decision-making processes, our target informants had to be knowledgeable with their organization's logistics PMS, the process of SCRM, and their organization's distribution service performance. In line with our research objective, 4,011 potential 
respondents were gathered from three databases of managers involved in logistics and SCM. They received an email that announced the survey and asked experts involved in the PMS domain of their respective logistics organization for registration via an online form, thus yielding an initial sample of 1,063 registered candidates. Only they received a link to the online survey.

To increase the response rate, three reminder emails were used. After eliminating nine data sets because of missing data, a set of 431 responses was used for our analysis, which corresponds to a response rate of $40,5 \%$. Within these data sets, a remainder of less than $1 \%$ missing item values was estimated using the expectation maximization algorithm (Dempster et al., 1977). A demographic summary of the companies and respondents is shown in Table 1.

Insert Table 1 Approximately Here

Besides focusing the initial sample on logistics and supply chain managers, respondent positions were analyzed to assess the validity of our data (Phillips, 1981). With an average tenure of more than 14 years and $82 \%$ of participants in senior positions, the answers reflect a high level of competency in our field of research.

Due to our single-informant approach, common method bias could be a problem (Podsakoff et al., 2003). We followed Chang et al. (2010) who suggest a number of procedural ex ante remedies, aimed at reducing the likelihood of the theory-in-use and consistency motive biases in the informant responses, and implemented them in the design stage of our research. Particularly, respondents were assured of the confidentiality and anonymity of the study, that there are no wrong or right answers, and that they should answer in an honest way. Moreover, to reduce the social desirability effect, items of independent and dependent variables were separated through survey questions that were unrelated to our model (Podsakoff et al., 2003) and adjacent survey 
questions were in most cases measured with different scale endpoints. We used Harman's singlefactor test (Harman, 1967) as an ex post statistical detection technique to detect a potential common method bias. An unrotated factor analysis of all measurement items reveals 4 factors with eigenvalues above 1 that explain $68.2 \%$ in total variance, where the first factor accounts for 33.0\% of variance. As the method assumes that, if common method bias is present, either (a) a single factor will emerge from the factor analysis or (b) one factor will account for the majority of the covariance among the measures (Podsakoff et al., 2003), no indication for a common method bias was found.

To test for late-response bias, the means of all items were compared between the first and last third of responses via $t$-test analysis (Armstrong and Overton, 1977). Results showed no significant differences $(p<0.05)$ for any of the items and therefore no indication for a late-response bias. Moreover, a test for non-response bias was conducted. 30 non-respondents were convinced to complete an abbreviated version of the survey that contained eight of this study's items. Again, an independent sample $t$-test that compared answers between the full respondent version and the short non-respondent version showed no significant differences $(p<0.05)$. Therefore, it can be assumed that non-response bias does not influence the results of this research.

\section{Measurement Scales}

All construct measures used for the survey relied upon multi-item measurement scales (see the Appendix for all measurement scales and items). A review of the existing logistics, SCM, and accounting literature provided items for the measurement scales. As the survey was sent to German logistics and supply chain managers, it was first developed in English, then translated into German, and finally back-translated into English to ensure validity, as recommended by Brislin (1976). Items were discussed with a group of ten academics and logistics practitioners 
during development of the survey to validate readability. As a result of the discussion, a few items were adapted to better fit our research context. Three further practitioners were involved for specific questions and final validation of the survey.

Both PMS use for attention focusing and PMS use for score keeping were measured with the scales of Vandenbosch (1999). For attention focusing, one item ("vocabulary in the organization”) was deemed confusing and therefore omitted. Instead, an item of Henri's (2006) scale (AF4) was added to ensure content validity and comprehensiveness.

Given the lack of empirical research on the monitoring of external turbulence in the supply chain context, no suitable instrument to measure PMS design for turbulence could be identified. Therefore, items were generated based on a review of extant SCRM and PMS literature (Ritchie and Brindley, 2007; Trkman and McCormack, 2009; Christopher and Holweg, 2011) and discussed with the group of ten researchers and practitioners involved in the development of the survey. First, statements were formulated to reflect a PMS that accounts for the monitoring of turbulence in the upstream and downstream supply chain environment, i.e., on supplier and on customer markets (e.g., Giannakis, 2007). Next, a discussion of the statements ensured that the items were applicable to the context of any logistics organization. Small adaptations were made during the translation process to enhance understandability for the target group of Germanspeaking logistics managers.

At the time when the questionnaire was developed, no scales existed that measure organizational resilience and could be used for the context of this research. Therefore, statements from conceptual SCRM research (Weick et al., 1999; Tang, 2006; Ponomarov and Holcomb, 2009) were used to generate items for the measurement of organizational resilience. In the process, it 
was made sure that the items specifically referred to the concept of resilience and not to other aspects of SCRM. After adapting the items to fit the context of our research, they were subsequently discussed with both researchers and practitioners and further refined. A scale later presented by Ambulkar et al. (2015) covers very similar aspects of resilience, which supports the soundness of our own scale.

Distribution service performance was measured using the established scale of Ellinger et al. (2000) where one item ("notifying customers in advance") was replaced with an item from the scale's adaptation by Stank et al. (2001) (DSP5) to better reflect the overall fulfillment of customer expectations in logistics operations.

Cronbach's alpha and composite reliability (CR) was used to assess the reliability of the measurement scales. The alpha values ranged between 0.83 and 0.90 and, similarly, the CR values ranged between 0.83 and 0.91 , which both indicate high reliability. Moreover, the average variances extracted (AVE) values ranged between 0.55 and 0.71 , which indicates that for each construct on average a large proportion of the variance of each indicator can be explained by the construct. The assumed construct dimensionality and convergent validity was supported by an exploratory factor analysis (EFA) and a subsequent confirmatory factor analysis (CFA) which indicates good model fit $\left(\chi^{2} / \mathrm{df}=1.76 ; \mathrm{CFI}=0.98 ; \mathrm{TLI}=0.97 ; \mathrm{RMSEA}=0.042\right)($ Garver and Mentzer, 1999). Further, a high significance of loadings for the scales' measurement items is confirmed by a lowest standardized regression path of 0.65 (AF4) and a lowest $t$-value of 13.63 (DSP2) (Gerbing and Anderson, 1988), as shown in the Appendix. 
Discriminant validity was examined both on the construct and item levels. First, as recommended by Voorhees et al. (2016), we used both the AVE-SV method (Fornell and Larcker, 1981) and the HTMT method (Henseler et al., 2015) to assess discriminant validity on the construct level. The former method assumes discriminant validity when, as in our case, the FornellLarcker criterion is met (i.e., the square root of the average variance extracted for any construct exceeds the correlation of this construct with any other construct, see Table 2). It has been suggested for the latter method that discriminant validity is likely to exist if all HTMT values are smaller than 0.85 (Voorhees et al., 2016). This criterion was also met. Second, on the item level, discriminant validity was assessed based on potential cross-loadings (Bollen, 1989). No substantial cross-loadings were found. In sum, no indications for any discriminant validity violations were found.

\section{Controls}

A logistics organization's actual exposure to upstream and downstream turbulence (i.e., on supplier and on customer markets) may influence the proposed relationships. To capture such a potential influence, we controlled for the exposure to external turbulence and operationalized this control variable along three items based on the SCRM literature (Braunscheidel and Suresh, 2009; Trkman and McCormack, 2009) (see Appendix). Additionally, other key organizational capabilities, besides organizational resilience, can be expected to influence distribution service performance as the overall outcome. Therefore, we incorporate customer-orientation and crossfunctional integration as two control variables, where customer-orientation is measured based on the scale of Narver and Slater (1990) and cross-functional integration based on the scales of Zacharia and Mentzer (2004) and Daugherty et al. (2009). Also, as the sample included both internal logistics departments of manufacturing and retailing companies (58\% of cases) and lo- 
gistics service providers ( $42 \%$ of cases), we included a binary control variable for the type of logistics organization to capture any influences that the different organizational setups may have on the proposed relationships.

\section{Results}

To test the hypotheses, the structural model (in model A without the control variables and in model B with the control variables) was calculated based on a maximum-likelihood estimation. The corresponding results are displayed in Table 3. Both model A and B have adequate fit (the values for model $\mathrm{B}$, which is of primary interest in hypotheses testing, are: $\chi^{2} / \mathrm{df}=2.49$; $\mathrm{CFI}=$ 0.91; TLI = 0.90; RMSEA $=0.059$ ).

Insert Table 3 Approximately Here

In the outcome part of the model, the hypothesized positive impact of PMS design for turbulence on organizational resilience (H1) receives clear support with a standardized path coefficient of +0.298 ( $p<0.001)$. Moreover, organizational resilience shows a strong positive and highly significant effect $(+0.265 ; p<0.001)$ on distribution service performance, supporting H2. The direct path from PMS design for turbulence to distribution service performance (H3) is nonsignificant $(+0.023 ; p=0.68)$, which supports H3. In an alternative model where organizational resilience was removed, this direct path was tested positive, which highlights that only by integrating organizational resilience into the model the relationships between these constructs can be fully understood.

Regarding the effect of upper management's PMS use focus on PMS design for turbulence, attention focusing shows a strong impact $(+0.553 ; p<0.001)$, supporting H4. In contrast, the hypothesized negative impact of a score keeping use on PMS design for turbulence (H5) finds no 
support $(-0.108 ; p=0.26)$. With respect to the explanatory power of the model $\left(\mathrm{R}^{2}\right)$, the antecedents explain 23\% of the variances in PMS design for turbulence, as well as $9 \%$ and $18 \%$ of variances in organizational resilience and distribution service performance, respectively.

To test the robustness of the results, a moderation analysis between the two basic types of logistics organizations in the sample, internal logistics departments of shippers on the one hand ( $n=251)$ and logistics service providers $(n=180)$ on the other hand was conducted. The results from $\chi^{2}$-difference tests show that for all hypothesized paths no significant differences exist $(p<$ 0.05) between internal logistics departments and logistics service providers, which underscores the generalizability of the results to different organizational contexts in logistics operations.

\section{Discussion}

In a first step, this study brings together SCRM and well-established concepts of management accounting, especially PMS, to both investigate SCRM from a management accounting perspective and to revisit management accounting procedures from an SCM perspective. It is shown that the general approach to managing and controlling has a substantial impact on the capability of companies to deal with external turbulence. Further, in seeking to understand why, in current supply chain practice, some organizations make strong use of supply chain risk metrics while others neglect them, we built on Henri's (2006) concept of upper management control and PMS design. Our results illustrate that the upper management, which itself has a general management focus and is not confined to SCM issues, has a strong role in driving or impeding PMS design for turbulence. Our findings-where an attention focusing PMS use explains a substantial share of PMS design for turbulence-underscore that upper-level managers realize the need for supply chain risk metrics when generally applying a management approach that uses PMS for attention focusing. These findings strengthen prior theoretical knowledge that an attention focus- 
ing use of PMS increases the diversity of the performance measures (Henri, 2006) and improves organizational competitiveness (Vandenbosch, 1999). This is also the case in specific domains of the company like SCM.

In a second step, this research builds upon strategic management theory to outline how the PMS design impacts organizational resilience and, in turn, operational performance. Here, the outcomes of PMS design for turbulence underscore the value of integrating the monitoring of external turbulence into the PMS as an established system of management control. It is a strong driver of organizational resilience as a key organizational capability (Melnyk et al., 2014). Additionally, we show that PMS design for turbulence as an intangible resource only improves operational performance (here we viewed distribution service performance) when a company prior succeeds in turning it into increased organizational resilience.

With respect to the control variables (see model B in comparison to model A), it is noteworthy that these do not significantly alter the effects of the antecedents on our focal construct, PMS design for turbulence, and also not of the focal variable on the capabilities and the performance outcome. The only significant effects are that the type of company (shippers vs. logistics service providers) and the degree of customer orientation influence distribution service performance (logistics service providers as well as highly customer oriented companies exhibit higher distribution service performance), and in that way slightly reduce the impact of organizational resilience on distribution service performance.

\section{Conclusion}

This research shows that it is useful to integrate management accounting and strategic management theory into SCM to extend the current knowledge of SCRM. Hereby, management and 
control, and organizational capabilities are connected to operational performance against the background of the relatively high degree of external turbulence companies have to deal with in today's supply chains. This research was guided by two research objectives. With respect to the objective, which was focused on the outcome of PMS design for turbulence, it was shown that accounting for external turbulence via metrics in PMS design increases organizational resilience and distribution service performance. This addressed the literature gap which existed regarding PMS as a relevant antecedent of supply chain-related organizational resilience of companies. With respect to the second objective, which was focused on antecedents of PMS design for turbulence, it was shown that an attention focusing use of the PMS by the upper management fosters incorporating the element of risk into the PMS of the company. This allows the use in multiperspective discussions in SCM, but also in management accounting and strategic management and addresses the literature gap regarding relevant links between PMS usage and management of supply-chain related risks.

\section{Managerial Implications}

The results of our study offer several insightful implications for supply chain managers. Given the need to manage supply chains in the context of higher levels of external turbulence, we provide clear support that the integration of supply chain risk metrics in the PMS of an organization can be a source of competitive advantage. A post-hoc analysis showed that even for organizations with a relatively low exposure to external turbulence the proposed relationships of our RBV perspective (resource $\rightarrow$ capability $\rightarrow$ performance) are still significant. Accordingly, logistics managers need to be aware that, even if they consider their organization to be less affected by external turbulence than others, PMS design for turbulence still is an enabler of distribution service performance. However, the results confirm that risk monitoring through an organ- 
ization’s PMS promises higher levels of performance only if logistics organizations manage to translate their risk awareness into resilient operations. Moreover, we have demonstrated that upper-level managers' mindsets play an essential role in accounting for turbulence in PMS design to support front-line managers and employees in daily operations. Hence, upper-level managers can draw conclusions in two principal fields:

First, they need to critically review the readiness of their PMS for the monitoring of external turbulence. If supply chain risk metrics are not used in their organization, they may want to reconsider PMS design, including their own role in selecting and prioritizing the mix of measures. One context in which supply chain risk metrics often lack are a strong focus on score keeping, whereas accounting for new SCM requirements in PMS design is easier when management is trying to gain a broader perspective. Although upper management's mindsets and hence the focus of control in an organization will not change overnight, moving towards an attention focusing PMS use will gradually prepare an organization against supply chain risks. Here, it will be of pivotal importance to involve front-line managers and employees with a sound understanding of risk monitoring needs in daily operations.

Second, as the mere use and reporting of risk metrics does not imply higher levels of performance by itself but through organizational resilience only, a learning process is required to truly leverage the benefits arising from risk monitoring. From a managerial perspective, this is an important finding which, at first glance, contradicts the often cited phrase "what gets measured gets done” (e.g., Otley, 1999). At second glance, it confirms that SCRM cannot follow the cybernetic control logic often used for financial controlling where goals are set in advance and compared to actual results (Hofstede, 1978). As supply chain risk represents an external factor, it is mostly impossible or inappropriate to monitor results against predefined goals. Tracking the 
potential impact of external turbulence, for example, cannot follow a cybernetic logic. However, upper-level and front-line managers can jointly ensure that the information provided by supply chain risk metrics actually translates into the capability to better cope with supply chain risk.

\section{Limitations and Future Research}

We acknowledge the limitations of our study and outline promising avenues for further research. First, data were solely collected in Germany which may limit the generalizability of findings (Wagner and Bode, 2006). It has been found that Germans typically restrict information flows to narrow channels because of compartmentalization (Hall and Hall, 2000) and the German culture has been described as risk averse (Taplin, 2005). This might influence the empirical model, as PMS build on information flows and, therefore, risk aversion could impact PMS design for turbulence. The insignificance of the path observed when testing $\mathrm{H} 5$ might also be specific to Germany. Second, in seeking to bring together SCRM with PMS as an established management control system, we had to measure PMS design for turbulence with rather general items to fit the different organizational contexts of participating companies. Moreover, no "hard facts" were drawn upon to measure distribution service performance, though the high share of participating key-informants provides reliable results.

Regarding the outcome effect, we need to note that, while PMS design for turbulence is a very strong and significant driver of organizational resilience, it only explains $9 \%$ of its variance, indicating that PMS design is only one of many antecedents that substantially affect the resilience of logistics organizations.

In further investigating the role of PMS for risk management, it would be interesting to explore more specific supply chain setups, including the identification of particular risk metrics being used in managerial practice. Here, we would strongly encourage case study research that 
would not only contribute to SCRM research, but at the same time allow "revisiting the management accounting procedures that are used to evaluate different supply chain decisions" as proposed by Christopher and Holweg (2011). A multi-case study of different companies involved in a supply chain may yield interesting insights into the relationship between PMS design for turbulence, organizational resilience, and overall supply chain resilience.

Moreover, in seeking to understand the drivers and impediments underlying PMS design for turbulence, our study focused on two types of PMS use as contingent variables for PMS design. Other organizational factors may also play an important role in this context. Besides investigating a broader scope of organizational culture for the role of management control systems in SCRM, examining other determinants of PMS design such as strategic priorities (Henri, 2006) would provide valuable contributions to the SCM and accounting literature. 


\section{References}

Abrahamsson, M., Christopher, M. and Stensson, B.-I. (2015), “Mastering supply chain management in an era of uncertainty at SKF", Global Business and Organizational Excellence, Vol. 34 No. 6, pp. 6-17.

Ambulkar, S., Blackhurst, J. and Grawe, S. (2015), “Firm’s resilience to supply chain disruptions: Scale development and empirical examination”, Journal of Operations Management, Vol. 33-34, pp. 111-122.

Amit, R. and Schoemaker, P.J. (1993), “Strategic assets and organizational rent”, Strategic Management Journal, Vol. 14 No. 1, pp. 33-46.

Armstrong, J.S. and Overton, T.S. (1977), “Estimating nonresponse bias in mail surveys”, Journal of Marketing Research, Vol. 14 No. 3, pp. 396-402.

Atkinson, A.A., Balakrishnan, R., Booth, P., Cote, J.M., Groot, T., Uliana, E. and Wu, A. (1997), "New directions in management accounting research", Journal of Management Accounting Research, Vol. 9, pp. 79-108.

Barney, J.B. (1991), “Firm resources and sustainable competitive advantage”, Journal of Management, Vol. 17 No. 1, pp. 99-120.

Barney, J.B. (2012), "Purchasing, supply chain management and sustained competitive advantage: The relevance of resource-based theory”, Journal of Supply Chain Management, Vol. 48 No. 2, pp. 3-6.

Björklund, M., Martinsen, U. and Abrahamsson, M. (2012), "Performance measurements in the greening of supply chains”, Supply Chain Management: An International Journal, Vol. 17 No. 1, pp. 29-39.

Blome, C. and Schoenherr, T. (2011), "Supply chain risk management in financial crises: A multiple case-study approach”, International Journal of Production Economics, Vol. 134 No. 1, pp. 43-57.

Bollen, K.A. (1989), Structural Equations with Latent Variables, Wiley, New York, NY.

Braunscheidel, M.J. and Suresh, N.C. (2009), “The organizational antecedents of a firm’s supply chain agility for risk mitigation and response”, Journal of Operations Management, Vol. 27 No. 2, pp. 119-140.

Brislin, R.W. (1976), “Comparative research methodology: Cross-cultural studies”, International Journal of Psychology, Vol. 11 No. 3, pp. 215-229. 
Burchell, S., Clubb, C., Hopwood, A., Hughes, J. and Nahapiet, J. (1980), “The roles of accounting in organizations and society”, Accounting, Organizations and Society, Vol. 5 No. 1, pp. 5-27.

Calantone, R., Garcia, R. and Droege, C. (2003), “The effects of environmental turbulence on new product development strategy planning”, Journal of Product Innovation Management, Vol. 20 No. 2, pp. 90-103.

Carpenter, M.A., Geletkanycz, M.A. and Sanders, W.G. (2004), "Upper echelons research revisited: Antecedents, elements, and consequences of top management team composition”, Journal of Management, Vol. 30 No. 6, pp. 749-778.

Chan, H.K., Wang, W.Y., Luong, L.H. and Chan, F.T. (2009), "Flexibility and adaptability in supply chains: a lesson learnt from a practitioner", Supply Chain Management: An International Journal, Vol. 14 No. 6, pp. 407-410.

Chang, S.-J., van Witteloostuijn, A. and Eden, L. (2010), “Common method variance in international business research”, Journal of International Business Studies, Vol. 41 No. 2, pp. 178184.

Christopher, M. and Holweg, M. (2011), “'Supply chain 2.0': Managing supply chains in the era of turbulence”, International Journal of Physical Distribution \& Logistics Management, Vol. 41 No. 1, pp. 63-82.

Christopher, M., Mena, C., Khan, O. and Yurt, O. (2011), “Approaches to managing global sourcing risk”, Supply Chain Management: An International Journal, Vol. 16 No. 2, pp. $67-81$.

Cooper, M.C., Lambert, D.M. and Pagh, J.D. (1997), "Supply chain management: More than a new name for logistics", The International Journal of Logistics Management, Vol. 8 No. 1, pp. 1-14.

Coutu, D.L. (2002), “How resilience works”, Harvard Business Review, Vol. 80 No. 5, pp. 4655.

Daugherty, P., Chen, H., Mattioda, D. and Grawe, S. (2009), "Marketing/logistics relationships: Influence on capabilities and performance”, Journal of Business Logistics, Vol. 30 No. 1, pp. 1-18.

Dempster, A., Laird, N. and Rubin, D. (1977), "Maximum likelihood from incomplete data via the EM algorithm", Journal of the Royal Statistical Society. Series B (Methodological), Vol. 39 No. 1 , pp. 1-38.

Durach, C.F., Wieland, A. and Machuca, J.A.D. (2015), “Antecedents and dimensions of supply chain robustness: A systematic literature review”, International Journal of Physical Distribution \& Logistics Management, Vol. 45 No. 1-2, pp. 118-137. 
Ellinger, A.E., Daugherty, P.J. and Keller, S.B. (2000), “The relationship between marketing/logistics interdepartmental integration and performance in U.S. manufacturing firms: An empirical analysis”, Journal of Business Logistics, Vol. 21 No. 1, pp. 1-22.

Evans, J. (2004), “An exploratory study of performance measurement systems and relationships with performance results”, Journal of Operations Management, Vol. 22 No. 3, pp. 219-232.

Feldman, M.S. and March G.J. (1981), "Information in organizations as signal and symbol”, Administrative Science Quarterly, Vol. 26 No. 2, pp. 171-186.

Fornell, C. and Larcker, D.F. (1981), "Evaluating structural equation models with unobservable variables and measurement error", Journal of Marketing Research, Vol. 18 No. 1, pp. 3950 .

Garver, M.S. and Mentzer, J.T. (1999), "Logistics research methods: Employing structural equation modeling to test for construct validity", Journal of Business Logistics, Vol. 20 No. 1, pp. 33-58.

Gerbing, D. and Anderson, J. (1988), “An updated paradigm for scale development incorporating unidimensionality and its assessment”, Journal of Marketing Research, Vol. 25 No. 2, pp. 186-192.

Giannakis, M. (2007), "Performance measurement of supplier relationships”, Supply Chain Management: An International Journal, Vol. 12 No. 6, pp. 400-411.

Grant, R.M. (1991), "The resource-based theory of competitive advantage: Implications for strategy formulation”, California Management Review, Vol. 33 No. 3, pp. 114-135.

Gunasekaran, A. and Kobu, B. (2007), "Performance measures and metrics in logistics and supply chain management: A review of recent literature (1995-2004) for research and applications”, International Journal of Production Research, Vol. 45 No. 12, pp. 2819-2840.

Hall, E.T. and Hall, M.R. (2000), Understanding Cultural Differences: Germans, French and Americans, Intercultural Press, Yarmouth, ME.

Hallikas, J., Karvonen, I., Pulkkinen, U., Virolainen V.-M. and Tuominen, M. (2004), “Risk management processes in supplier networks", International Journal of Production Economics, Vol. 90 No. 1, pp. 47-58.

Hamel, G. and Välikangas, L. (2003), “The quest for resilience”, Harvard Business Review, Vol. 81 No. 9, pp. 52-63.

Harman, H.H. (1967), Modern Factor Analysis. University of Chicago Press, Chicago, IL.

Hendricks, K.B. and Singhal, V.R. (2003), "The effect of supply chain glitches on shareholder wealth”, Journal of Operations Management, Vol. 21 No. 5, pp. 501-522. 
Henri, J. (2006), “Organizational culture and performance measurement systems”, Accounting, Organizations and Society, Vol. 31 No. 1, pp. 77-103.

Henri, J. (2008), “Taxonomy of performance measurement systems”, Advances in Management Accounting, Vol. 17, pp. 247-288.

Henseler, J., Ringle, C.M. and Sarstedt, M. (2015), “A new criterion for assessing discriminant validity in variance-based structural equation modeling”, Journal of the Academy of Marketing Science, Vol. 43 No. 1, pp. 115-135.

Hofstede, G. (1978), “The poverty of management control philosophy”, Academy of Management Review, Vol. 3 No. 3, pp. 450-461.

Ignatiadis, I. and Nandhakumar J. (2006), "The impact of enterprise systems on organizational resilience”, Journal of Information Technology, Vol. 22 No. 1, pp. 36-43.

Ittner, C.D. and Larcker, D.F. (1998), "Innovations in performance measurement: Trends and research implications”, Journal of Marketing Research, Vol. 10 No. 2, pp. 205-238.

Johnson, N., Elliott, D. and Drake, P. (2013), "Exploring the role of social capital in facilitating supply chain resilience”, Supply Chain Management: An International Journal, Vol. 18 No. 3, pp. 324-336.

Kennerley, M. and Neely, A. (2003), "Measuring performance in a changing business environment”, International Journal of Operations \& Production Management, Vol. 23 No. 2, pp. 213-229.

Kilfoyle, E., Richardson, A.J. and MacDonald, L.D. (2013), "Vernacular accountings: Bridging the cognitive and the social in the analysis of employee-generated accounting systems", Accounting, Organizations and Society, Vol. 38 No. 5, pp. 382-396.

Koufteros, X., Verghese, A. and Lucianetti, L. (2014), "The effect of performance measurement systems on firm performance: A cross-sectional and a longitudinal study", Journal of Operations Management, Vol. 32 No. 6, pp. 313-336.

Malik, Y., Niemeyer, A. and Ruwadi, B. (2011), "Building the supply chain of the future", McKinsey Quarterly, No. 1, pp. 62-71.

Malmi, T. and Brown, D.A. (2008), "Management control systems as a package: Opportunities, challenges and research directions", Management Accounting Research, Vol. 19 No. 4, pp. 287-300.

Manuj, I. and Mentzer, J.T. (2008), “Global supply chain risk management”, Journal of Business Logistics, Vol. 29 No. 1, pp. 133-155. 
McCann, J., Selsky, J. and Lee, J. (2009), "Building agility, resilience, and performance in turbulent environments”, People and Strategy, Vol. 32 No. 3, pp. 44-51.

Melnyk, S.A., Closs, D.J., Griffis, S.E., Zobel, C.W. and Macdonald, J.R. (2014), "Understanding supply chain resilience”, Supply Chain Management Review, Vol. 18 No. 1, pp. 34-41.

Menon, A. and Varadarajan, P.R. (1992), “A model of marketing knowledge use within firms”, Journal of Marketing, Vol. 56 No. 4, pp. 53-71.

Mentzer, J.T., Flint, D.J. and Hult, G.T. (2012), "Logistics service quality as a segmentcustomized process”, Journal of Marketing, Vol. 65 No. 4, pp. 82-104.

Narver, J.C. and Slater, S.F. (1990), "The effect of a market orientation on business profitability”, Journal of Marketing, Vol. 54 No. 4, pp. 20-35.

Neely, A., Gregory, M. and Platts, K. (2005), “Performance measurement system design”, International Journal of Operations \& Production Management, Vol. 25 No. 12, pp. 1228-1263.

Otley, D. (1999), "Performance management: A framework for management control systems research”, Management Accounting Research, Vol. 10 No. 4, pp. 363-382.

Phillips, L.W. (1981), “Assessing measurement error in key informant reports: A methodological note on organizational analysis in marketing”, Journal of Marketing Research, Vol. 18 No. 4, pp. 395-415.

Podsakoff, P.M., MacKenzie, S.B., Lee, Y.-L. and Podsakoff, N.P. (2003), “Common method biases in behavioral research: A critical review of the literature and recommended remedies”, Journal of Applied Psychology, Vol. 88 No. 5, pp. 879-903.

Ponomarov, S.Y. and Holcomb, M.C. (2009), "Understanding the concept of supply chain resilience”, The International Journal of Logistics Management, Vol. 20 No. 1, pp. 124-143.

Rasid, S.Z.A., Golshan, N.M., Ismail, W.K.W. and Ahmad, F.S. (2012), "Risk management, performance measurement and organizational performance: A conceptual framework", $3^{\text {rd }}$ International Conference on Business and Economic Research 2012 Proceedings, pp. $1702-1715$.

Rhea, M.J. and Shrock, D.J. (1987), "Measuring the effectiveness of physical distribution customer service programs", Journal of Business Logistics, Vol. 8 No. 1, pp. 31-45.

Ridgway, V.F. (1956), "Dysfunctional consequences of performance measurements”, Administrative Science Quarterly, Vol. 1 No. 2, pp. 240-247.

Ritchie, B. and Brindley, C. (2007), "Supply chain risk management and performance: A guiding framework for future development”, International Journal of Operations \& Production Management, Vol. 27 No. 3, pp. 303-322. 
Schaeffer, U. and Steiners, D. (2003), “Zur Nutzung von Controllinginformationen”, Management Accounting, No. 9, pp. 1-36.

Scholten, K., Sharkey-Scott, P. and Fynes, B. (2014), "Mitigation processes - antecedents for building supply chain resilience”, Supply Chain Management: An International Journal, Vol. 19 No. 2, pp. 211-228.

Sheffi, Y. and Rice Jr., J.B. (2005), “A supply chain view of the resilient enterprise”, MIT Sloan Management Review, Vol. 47 No. 1, pp. 40-48.

Simchi-Levi, D., Schmidt, W. and Wei, Y. (2014), "From superstorms to factory fires: Managing unpredictable supply-chain disruptions”, Harvard Business Review, Vol. 92 No. 1-2, pp. 96-101.

Simon, H.A., Guetzkow, H., Kozmetsky, G. and Tyndall, G. (1954), Centralization vs Decentralization in Organizing the Controllers' Department, Controllership Foundation Inc., New York, NY.

Simons, R. (1990), "The role of management control systems in creating competitive advantage: New perspectives”, Accounting, Organizations and Society, Vol. 15 No. 1-2, pp. 127-143.

Sodhi, M.S., Son, B.-G. and Tang, C.S. (2012), “Researchers’ perspectives on supply chain risk management”, Production and Operations Management, Vol. 21 No. 1, pp. 1-13.

Springinklee, M. and Wallenburg, C.M. (2012), "Improving distribution service performance through effective production and logistics integration”, Journal of Business Logistics, Vol. 33 No. 4, pp. 309-323.

Stank, T.P., Keller, S.B. and Daugherty, P.J. (2001), "Supply chain collaboration and logistical service performance”, Journal of Business Logistics, Vol. 22 No. 1, pp. 29-48.

Tang, C.S. (2006), "Perspectives in supply chain risk management”, International Journal of Production Economics, Vol. 103 No. 2, pp. 451-488.

Taplin, R. (2005), Risk Management and Innovation in Japan, Britain, and the United States, Routledge, New York, NY.

Tomer, J. (1987), Organizational Capital, Praeger Publishing, New York, NY.

Trkman, P. and McCormack, K. (2009), "Supply chain risk in turbulent environments: A conceptual model for managing supply chain network risk", International Journal of Production Economics, Vol. 119 No. 2, pp. 247-258.

van Hoek, R.I. (2000), “The purchasing and control of supplementary third-party logistics services”, Journal of Supply Chain Management, Vol. 36 No. 3, pp. 14-26. 
Vandenbosch, B. (1999), “An empirical analysis of the association between the use of executive support systems and perceived organizational competitiveness", Accounting, Organizations and Society, Vol. 24 No. 1, pp. 77-92.

Voorhees, C.M., Brady, M.K., Calantone, R. and Ramirez, E. (2016), “Discriminant validity testing in marketing: an analysis, causes for concern, and proposed remedies”, Journal of the Academy of Marketing Science, Vol. 44 No. 1, pp. 119-134.

Wagner, S.M. and Bode, C. (2006), “An empirical investigation into supply chain vulnerability”, Journal of Purchasing and Supply Management, Vol. 12 No. 6, pp. 301-312.

Wagner, S.M. and Bode, C. (2008), “An empirical examination of supply chain performance along several dimensions of risk”, Journal of Business Logistics, Vol. 29 No. 1, pp. 307325.

Weick, K.E., Sutcliffe, K.M. and Obstfeld, D. (1999), “Organizing for high reliability: Processes of collective mindfulness”, Research in Organizational Behavior, Vol. 21, pp. 13-81.

Wieland, A., Handfield, R. and Durach, C.F. (2016), "Mapping the landscape of future research themes in supply chain management”, Journal of Business Logistics, Vol. 37 No. 3, pp. 1-8

Wieland, A. and Wallenburg, C.M. (2012), "Dealing with supply chain risks: Linking risk management practices and strategies to performance”, International Journal of Physical Distribution \& Logistics Management, Vol. 42 No. 10, pp. 887-905.

Wieland, A. and Wallenburg, C.M. (2013), “The influence of relational competencies on supply chain resilience: A relational view”, International Journal of Physical Distribution \& Logistics Management, Vol. 43 No. 4, pp. 300-320.

Wong, C., Skipworth, H., Godsell, J. and Achimugu, N. (2012), “Towards a theory of supply chain alignment enablers: a Systematic Literature Review”, Supply Chain Management: An International Journal, Vol. 17 No. 4, pp. 419-437.

Zacharia, Z.G. and Mentzer, J.T. (2004), “Logistics salience in a changing environment”, Journal of Business Logistics, Vol. 25 No. 1, pp. 187-210. 


\section{Appendix}

\section{Appendix A. Measurement Scales and Items}

Mean SD $\begin{gathered}\text { Stand. } \\ \text { Weight }\end{gathered}$

Attention focusing (Vandenbosch, 1999)

(Cronbach's alpha $=0.87$ AVE $=0.63 ; \mathrm{CR}=0.87$ )

Please rate the extent to which your upper management currently uses PMS to ...

\begin{tabular}{llllll}
\hline AF1 & ... tie the organization together. & 4.99 & 1.63 & 0.84 & 14.34 \\
AF2 & ... enable the organization to focus on our critical success factors. & 4.92 & 1.53 & 0.83 & 14.26 \\
AF3 & $\ldots$ provide a common view of the organization. & 4.94 & 1.60 & 0.84 & 14.33 \\
AF4 & $\ldots$ enable discussion in meetings of superiors, sub-ordinates and peers. & 4.71 & 1.69 & 0.65 & fixed \\
AF5 & $\ldots$ enable continual challenge and debate of underlying results, assump- & Eliminated in scale refine- \\
\multicolumn{3}{c}{ tions and action plans* } & \multicolumn{5}{c}{ ments } \\
\hline
\end{tabular}

Score keeping (Vandenbosch, 1999)

(Cronbach's alpha $=0.90 ; \mathrm{AVE}=0.71 ; \mathrm{CR}=0.91$ )

Please rate the extent to which your upper management currently uses PMS to ...

\begin{tabular}{llrrrr}
\hline SK1 & $\ldots$ track progress towards goals. & 5.69 & 1.35 & 0.86 & 22.21 \\
SK2 & $\ldots$ review key performance indicators. & 5.35 & 1.47 & 0.80 & 19.77 \\
SK3 & $\ldots$ monitor results. & 5.75 & 1.31 & 0.86 & 22.27 \\
SK4 & $\ldots$... compare outcomes to expectations. & 5.74 & 1.29 & 0.85 & fixed \\
\hline
\end{tabular}

PMS design for turbulence (new scale)

(Cronbach's alpha $=0.84 ; \mathrm{AVE}=0.65 ; \mathrm{CR}=0.85$ )

Please rate the extent to the following items describe the PMS of your logistics organization:

\begin{tabular}{lllll}
\hline $\begin{array}{l}\text { PDT1 We use specific risk metrics to understand the impact of external turbu- } \\
\text { lence on our business. }\end{array}$ & 3.64 & 1.86 & 0.80 & 15.37 \\
PDT2 We use early warning indicators to anticipate and plan for fluctuations. & 3.81 & 1.76 & 0.87 & 15.84 \\
PDT3 We measure market volatility in order to be able to react on time. & 3.50 & 1.76 & 0.73 & fixed \\
\hline
\end{tabular}

\section{Organizational resilience (new scale)}

(Cronbach's alpha $=0.83$; AVE $=0.63 ; \mathrm{CR}=0.83$ )

Please rate the extent to the following items describe your logistics organization:

\begin{tabular}{llllll}
\hline OR1 & $\begin{array}{l}\text { Our logistics organization has a strong ability to cope with external risk } \\
\text { or turbulence. }\end{array}$ & $\begin{array}{l}5.00 \\
\text { OR2 }\end{array}$ & $\begin{array}{l}1.30 \\
\text { We are well prepared to sustain operations in a turbulent market envi- }\end{array}$ & 0.83 & 16.51 \\
$\begin{array}{l}\text { ronment and to recover quickly afterwards. } \\
\text { OR3 }\end{array}$ & $\begin{array}{l}\text { We have the capacity to adjust required functions under challenging or } \\
\text { straining conditions. }\end{array}$ & 5.24 & 1.19 & 0.69 & fixed \\
\hline
\end{tabular}

All above items were measured with 7-point Likert scales ranging from " 1 = not at all" to " 7 = to a very great extent". 
Distribution service performance (Ellinger et al., 2000; Stank et al., 2001)

(Cronbach's alpha $=0.86 ; \mathrm{AVE}=0.55 ; \mathrm{CR}=0.86$ )

Please rate your logistics organization's performance in comparison to competitors:

DSP1 The ability to meet quoted or anticipated delivery dates and quantities on a consistent basis.

$\begin{array}{llll}5.16 & 1.08 & 0.76 & 14.10\end{array}$

$\begin{array}{llllll}\text { DSP2 The ability to respond to the needs and wants of key customers. } & 5.40 & 1.11 & 0.69 & 13.63\end{array}$

DSP3 The ability to accommodate delivery times for specific customers. $\quad \begin{array}{llllll}5.22 & 1.13 & 0.67 & 14.50\end{array}$

$\begin{array}{llllll}\text { DSP4 The adherence to customer specifications. } & 5.35 & 0.98 & 0.71 & 17.26\end{array}$

DSP5 The global judgment regarding the extent to which logistics performance
matches customer expectations.

Items for distribution service performance were measured on a scale from " $1=$ much worse" to " 7 = much better than competitors". 


\section{Appendix B. Controls}

\section{Exposure to external turbulence (new scale)}

Please rate the extent of fluctuations in your logistics organization's environment:

Mean SD

MT1 Our environment is characterized by a high number of ongoing fluctuations

(e.g. raw material prices).

$3.78 \quad 1.03$

MT2 Our customer demand is subject to very high fluctuations. $\quad 3.51 \quad 1.03$

MT3 The supply of our (sub-)suppliers is subject to very high fluctuations.

$2.90 \quad 1.00$

Items were measured with a 7-point Likert scale ranging from " $1=$ not at all" to " 7 = to a very great extent".

Customer orientation (Narver and Slater, 1990)

Please rate the extent to which the following items describe your logistics organization:

Mean SD

CO1 We have a very good understanding of customer needs.

$5.72 \quad 1.08$

CO2 There is a high commitment to serving customers' needs.

$5.62 \quad 1.17$

CO3 We have very clear objectives regarding customer satisfaction

$5.40 \quad 1.50$

Items were measured with a 7-point Likert scale ranging from " $1=$ I strongly disagree" to "7 = I strongly agree".

Cross-functional integration (Zacharia and Mentzer, 2004; Daugherty et al., 2009)

Please rate the extent to which the following items describe your logistics organization:

CFI1 Within our organization cross-functional work teams are extensively utilized for managing day-to-day operations.

CFI2 Within our organization, employees are encouraged to work together with $\quad 5.05 \quad 1.54$ colleagues from other functional areas.

CFI3 Managers in our organization are strongly encouraged to share information $\quad 5.40 \quad 1.47$ and provide input to other functional areas.

CFI4 Within our organization, employees from different functional areas are $\quad 4.98 \quad 1.53$ strongly encouraged to share resources.

CFI5 Managers across our organization work together in (informal) teams.

Items were measured with a 7-point Likert scale ranging from " $1=$ I strongly disagree" to "7 = I strongly agree”.

Type of logistics organization (new scale, binary coded)

Internal logistics department of manufacturing/retail company (0)

$n=251$ (58\% of sample)

Logistics service provider (1)

$n=180$ (42\% of sample) 


\section{Appendix C. Exploratory Factor Analysis}

\begin{tabular}{|c|c|c|c|c|c|}
\hline & Factor 1 & Factor 2 & Factor 3 & Factor 4 & Factor 5 \\
\hline AF1 & 0.756 & & & & \\
\hline AF2 & 0.800 & & & & \\
\hline AF3 & 0.837 & & & & \\
\hline AF4 & 0.576 & & & & \\
\hline SK1 & & 0.669 & & & \\
\hline SK2 & & 0.595 & & & \\
\hline SK3 & & 0.928 & & & \\
\hline SK4 & & 0.905 & & & \\
\hline PDT1 & & & 0.826 & & \\
\hline PDT2 & & & 0.861 & & \\
\hline PDT3 & & & 0.710 & & \\
\hline OR1 & & & & 0.808 & \\
\hline OR2 & & & & 0.861 & \\
\hline OR3 & & & & 0.698 & \\
\hline DSP1 & & & & & 0.746 \\
\hline DSP2 & & & & & 0.710 \\
\hline DSP3 & & & & & 0.681 \\
\hline DSP4 & & & & & 0.722 \\
\hline DSP5 & & & & & 0.841 \\
\hline
\end{tabular}

Note: Only factor loadings above 0.30 are displayed. 


\section{Figure 1}

\section{Conceptual Research Model}

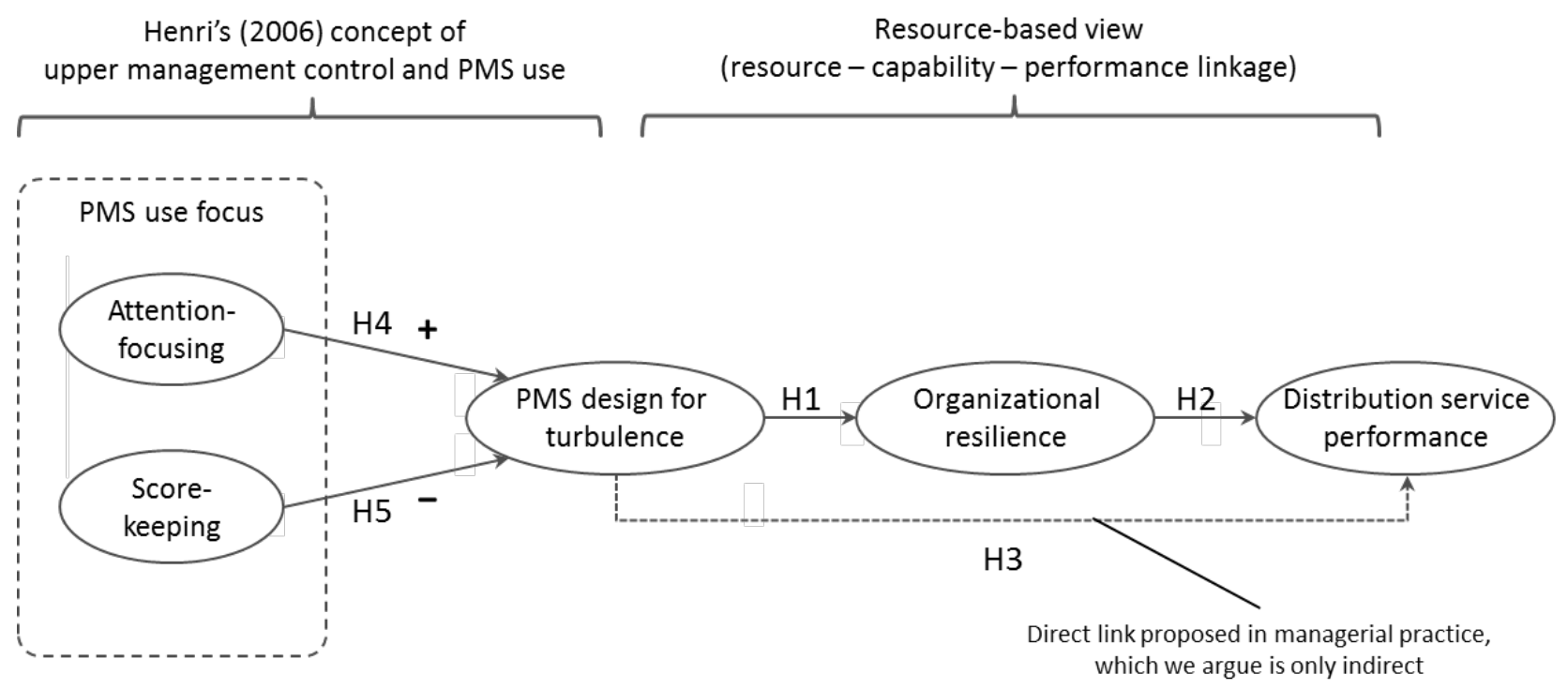




\section{Table 1}

\section{Respondent Demographics}

\begin{tabular}{lc}
\hline Industry & Percent \\
\hline Automotive & $12 \%$ \\
Chemicals and pharmaceuticals & $7 \%$ \\
Consumer goods & $11 \%$ \\
High-tech and electronics & $5 \%$ \\
Logistics services & $42 \%$ \\
Machinery and equipment & $11 \%$ \\
Other industries & $12 \%$ \\
\hline Job title of respondents & \\
\hline Top level executive & $24 \%$ \\
Director & $31 \%$ \\
Senior manager & $27 \%$ \\
Manager & $12 \%$ \\
Non-executive & $6 \%$ \\
\hline Number of logistics employees & \\
\hline Less than 50 & $39 \%$ \\
50 to 249 & $27 \%$ \\
250 to 999 & $18 \%$ \\
1,000 to 9,999 & $12 \%$ \\
10,000 or more & $4 \%$ \\
\hline
\end{tabular}




\section{Table 2}

Correlation Matrix among Latent Variables (Square Root of Average Variance Extracted on the Diagonal)

\begin{tabular}{|l|c|c|c|c|c|}
\cline { 2 - 5 } \multicolumn{1}{c|}{} & $(1)$ & $(2)$ & (3) & (4) & (5) \\
\hline (1) Attention focusing & $\mathbf{0 . 7 9 4}$ & & & & \\
\hline (2) Score keeping & 0.792 & $\mathbf{0 . 8 4 3}$ & & & \\
\hline (3) PMS design for turbulence & 0.460 & 0.322 & $\mathbf{0 . 8 0 6}$ & & \\
\hline (4) Organizational resilience & 0.308 & 0.264 & 0.283 & $\mathbf{0 . 7 9 4}$ & \\
\hline (5) DSP & 0.210 & 0.164 & 0.142 & 0.382 & $\mathbf{0 . 7 4 2}$ \\
\hline
\end{tabular}




\section{Table 3}

\section{Structural Equation Model without and with Controls}

\begin{tabular}{|c|c|c|c|c|}
\hline \multirow[t]{2}{*}{ Parameter } & \multicolumn{2}{|c|}{$\begin{array}{l}\text { Model A: } \\
\text { Structural equation model } \\
\text { without controls }\end{array}$} & \multicolumn{2}{|c|}{$\begin{array}{l}\text { Model B: } \\
\text { Structural equation model } \\
\text { with controls }\end{array}$} \\
\hline & Estimate & $p$-value & Estimate & $p$-value \\
\hline PMS design for turbulence $\rightarrow$ Organizational resilience $(\mathrm{H} 1)$ & 0.298 & $* * *$ & 0.298 & $* * *$ \\
\hline Organizational resilience $\rightarrow$ DSP (H2) & 0.368 & $* * *$ & 0.265 & $* * *$ \\
\hline PMS design for turbulence $\rightarrow$ DSP (H3) & 0.044 & 0.427 & 0.023 & 0.676 \\
\hline Attention focusing $\rightarrow$ PMS design for turbulence (H4) & 0.557 & $* * *$ & 0.553 & $* * *$ \\
\hline Score keeping $\rightarrow$ PMS design for turbulence (H5) & -0.110 & 0.250 & -0.108 & 0.258 \\
\hline External turbulence $\rightarrow$ PMS design for turbulence (control) & & & 0.071 & 0.220 \\
\hline External turbulence $\rightarrow$ Organizational resilience (control) & & & 0.003 & 0.957 \\
\hline External turbulence $\rightarrow$ DSP (control) & & & -0.093 & 0.117 \\
\hline Type of Log. Organization $\rightarrow$ PMS design for turbulence (control) & & & -0.041 & 0.382 \\
\hline Type of Log. Organization $\rightarrow$ Organizational resilience (control) & & & -0.028 & 0.578 \\
\hline Type of Log. Organization $\rightarrow$ DSP (control) & & & 0.198 & $* * *$ \\
\hline Customer orientation $\rightarrow$ DSP (control) & & & 0.258 & $* * *$ \\
\hline Cross-functional integration $\rightarrow$ DSP (control) & & & 0.025 & 0.625 \\
\hline $\mathrm{R}^{2}$ PMS design for turbulence & 0.225 & & 0.230 & \\
\hline $\mathrm{R}^{2}$ Organizational resilience & 0.089 & & 0.091 & \\
\hline $\mathrm{R}^{2} \mathrm{DSP}$ & 0.147 & & 0.183 & \\
\hline
\end{tabular}

Note: $* * * p$-value $<0.001$ 